\title{
29. A MODEL OF SEDIMENTATION ON A MOVING PLATE, WITH AN APPLICATION TO THE HISTORY OF THE NORTH PACIFIC
}

\author{
George Z. Forristall, Shell Development Company, Houston, Texas
}

\section{INTRODUCTION}

The sedimentary history of an ocean basin is controlled by complicated variations in such factors as the sources of sediments, their solubilities, and the motions of the oceanic crust. However, important large-scale features and basic relationships can be investigated with vastly simplified models such as the one described here. The complexity required of a model is in part determined by the amount of data available; as gaps in our knowledge of the historical record are filled, more detailed models will be useful.

The features in the sedimentary record which suggested the development of the model are discussed elsewhere in this volume and in Heezen et al. (1973). Here we are concerned with the mathematics of the model and with several examples which match the available data more or less well.

The two major sources of oceanic sediments are windblown continental dust and the remains of organisms living in the ocean. Except near such exceptional sources as volcanoes, the dust contribution is relatively small and uniform over the basin, and leads, in first approximation, to a uniform rate of abyssal clay formation. In contrast, variations in organic productivity and solubility of organic remains lead to important and systematic regional differences in the rate of organic sedimentation.

The solution rates of the calcareous and siliceous tests that are the main organic sediment components are controlled by factors such as temperature and pressure. The result of the dependence is that carbonate and silica compensation depths exist below which no sedimentary record of ordinary organic productivity is found, as discussed by Berger (1967) and Peterson (1966).

However, anomalously high rates of productivity can deposit so much organic material that the solution mechanism does not operate rapidly enough to dissolve all the remains. For our purposes, the important location of such productivity is the narrow zone of equatorial upwelling between the northern and southern hemisphere current systems (Arrhenius, 1952).

The concepts of sea-floor spreading are important in a discussion of sedimentation because they provide a systematic framework for the motions of the oceanic crust below the compensation depth and beneath the equator. Crust is formed at mid-ocean ridges above the compensation depth but rapidly drops below it, effectively eliminating organic sedimentation except on those portions of the plate beneath the equator.

Basically the mathematics of a model describing these phenomena is a simple bookkeeping operation. Consider a section perpendicular to the ridge crest. Whatever the relative motion of the equatorial zone, it may be described in the model by its speed and width projected on the section. At each step in time, we must calculate which sedimentation rates apply to each point on the section and add that then deposited to the thickness already there. Then at suitable time intervals, isochrons can be drawn through the thickness generated to produce a model geologic section. Several parallel sections give a rather complete history of the basin, which may then be compared with the data obtained from boreholes.

Our model isochrons give more detail than those of Winterer (1972), who calculated total sediment thickness in the eastern Pacific, and now some data from the older western Pacific are available. The approximations in the model and coarseness of the data permit only qualitative comparisons, but the method still provides valuable information on the history of plate motion. In particular, since the position of the geographical equator relative to the plate is important in the model, it will be useful in studying absolute, as opposed to relative, plate motions.

\section{FORMULATION OF THE MODEL}

If the rate of formation of crust at a ridge crest is known, distance from the ridge is equivalent to the age of formation of that portion of the crust. Thus positions on a section perpendicular to the ridge are labelled by their age of formation, $A_{f}$, in millions of years before present. The ordinates of the output graphs will be thickness of sediment, and isochrons will be plotted which show the thickness of sediment deposited in given time intervals.

Let the age of an isochron be $A_{\ell}$, and the interval between isochrons be $10 \mathrm{~m} . \mathrm{y}$. Then to find how far isochron $A_{\ell}$ must be drawn above isochron $A_{\ell}+10$, we need to know for what portion of the 10 m.y. before $A_{\ell}$ the various sedimentation rates applied and multiply the rates by the appropriate time intervals. This must be done at enough values of $A_{f}$ so that a smooth curve may be drawn through the points determined.

The abyssal clay contribution is easily determined if its rate $R_{a}$ is constant. The time during which this rate applied is

$$
T_{a}=\min \left(10, A_{f}-A_{\ell}\right)
$$

where we obviously must limit the time of sedimentation to the time the crust existed. Then the thickness of the abyssal clay contribution is

$$
D_{a}=T_{a} R_{a}
$$

To get the complete thickness of sediment deposited, we must add to $D_{a}$ the organic contributions on those parts of the crust above the compensation depth or beneath the equatorial zone. 
First, it is useful to calculate the time after crust formation when the crust crossed below the compensation depth from

$$
A_{c}=\frac{C-F}{R_{s}-R_{c}}
$$

where $C$ is the compensation depth, $F$ the depth of crustal formation, $R_{S}$ the subsidence rate of the crust, and $R_{C}$ the rate of organic sedimentation above the compensation depth. For simplicity, the carbonate and silica compensation depths are taken as equal and the subsidence rate is constant, since we are only interested in the time at which subsidence carried the crust below the compensation depth. Then the length of time during the 10 m.y. before the isochron $A_{\ell}$ that a given spot on the crust was above the compensation depth is given by

$$
T_{c}=\left\{\begin{array}{cc}
\min \left(10, A_{f}-A_{\ell}\right) & \text { for } A_{\ell}>A_{f}-A_{c} \\
\min \left(A_{\ell}+10-A_{f}+A_{c},\right. & \text { for } A_{\ell}+10>A_{f} \\
\left.A_{f}-A_{\ell}\right) & -A_{c}>A_{\ell} \\
0 & \text { otherwise }
\end{array}\right.
$$

where the various cases reflect the fact that $T_{C}$ must be less than 10 and limited to the time during which the crust existed. Then the thickness from the organic sedimentation above the ridge crest is

$$
D_{c}=T_{c} R_{c}
$$

We are now ready to consider the equatorial organic contribution, and to do so, the location of the equatorial zone at a given time must be calculated. Let the location of the equator with respect to the ridge crest at the time the model begins be $T_{e}$, the width of the equatorial zone be $W$ m.y. on the crustal section, and the speed of the equator with respect to the ridge axis be $S$, expressed as a multiple of the plate's spreading speed and measured as the component of motion perpendicular to the ridge. Physically, it is more reasonable to think of the ridge crest moving, but all that matters is relative motion, and it is more convenient in formulating the model to consider the equator moving. For example, if $S=1$, the equator and plate move at the same speed, and the equatorial zone stays over the same range of $A_{f}$ on the plate. Since the section constructed is perpendicular to the ridge, the effective width of the equatorial zone on the section will be increased by a factor of $1 / \cos \theta$ if the angle between the ridge and the equator is $\theta$.

At a time $T$ after $T_{O}$, the starting time of the model, the equatorial zone extends from

to

$$
T_{e}+T S-W / 2
$$

$$
T_{e}+T S+W / 2,
$$

measured from the ridge axis. Now recall that positions on the plate are given by their age of formation, and thus the equatorial zone is above a given $A_{f}$ if

$$
\begin{gathered}
T_{o}+T_{e}+T(S-1)-W / 2 \leqslant A_{f} \leqslant \\
T_{o}+T_{e}+T(S-1)+W / 2 .
\end{gathered}
$$

That is, the equatorial zone is above $A_{f}$ for the range of times $T$ given by

$$
\begin{gathered}
A_{f}-T_{o}-T_{e}-W / 2 \leqslant T(S-1) \leqslant \\
A_{f}-T_{o}-T_{e}+W / 2 .
\end{gathered}
$$

The time $T$ is converted into time before present by the transformation

$$
T_{b}=T_{o}-T \text {. }
$$

Then through manipulations like those of Equation 4, we check that the range of $T_{b}$ is within the allowable limits. The case $S=1$ must be considered separately, but poses no special difficulty. Since plate motions may change in direction and speed, the model provides for changes in the equatorial parameters at various times. The formulas necessary are thus slightly more complicated than shown here, but are essentially the same.

The corrected time is then multiplied by the equatorial sedimentation rate and added to the sediment accumulation from other sources. Thus, being beneath the equator results in a faster sedimentation rate whether or not the crust is above the compensation depth. Turbidites and local terrigenous sedimentation could be added on an ad hoc basis, but it seems simpler to subtract their contribution from the data we are trying to match.

A computer program which performs the manipulations described above and automatically plots the results is described in the appendix. Some examples of the output of the program for simple choices of input parameters are shown in Figures 1,2, and 3. These examples are not meant to correspond to any particular case in nature, but illustrate some features of the model's operation.

In each figure the abscissa is the age of crust formation and the ordinate is thickness of crust. The lines plotted are isochrons whose ages can be read where they meet the abscissa. Figures 1,2, and 3 have the common parameters:

$$
\begin{array}{ll}
\text { Depth of crustal formation } & =300 \mathrm{~m} \\
\text { Compensation depth } & =3700 \mathrm{~m} \\
\text { Subsidence rate } & =35 \mathrm{~m} / \mathrm{m} . \mathrm{y} . \\
\text { Abyssal clay sedimentation rate } & =2 \mathrm{~m} / \mathrm{m} . \mathrm{y} . \\
\text { Ridge crest sedimentation rate } & =10 \mathrm{~m} / \mathrm{m} . \mathrm{y} .
\end{array}
$$

Figure 1 is particularly simple since it includes no equatorial crossing. Thus, there are only two sedimentary facies: a rapidly deposited basal carbonate layer covered by slowly accumulated abyssal clay. Note that as the crustal age increases, much greater ages of abyssal clay must be penetrated before the carbonate layer is reached.

In Figure 2 an equatorial zone of 30 m.y. effective width is centered 100 m.y. from the ridge crest and does not move with respect to the crest. Recall that distances are expressed in terms of crustal age in the model, and thus the equator is such a distance from the ridge crest that the plate formed at the beginning of the model 200 m.y. ago will 


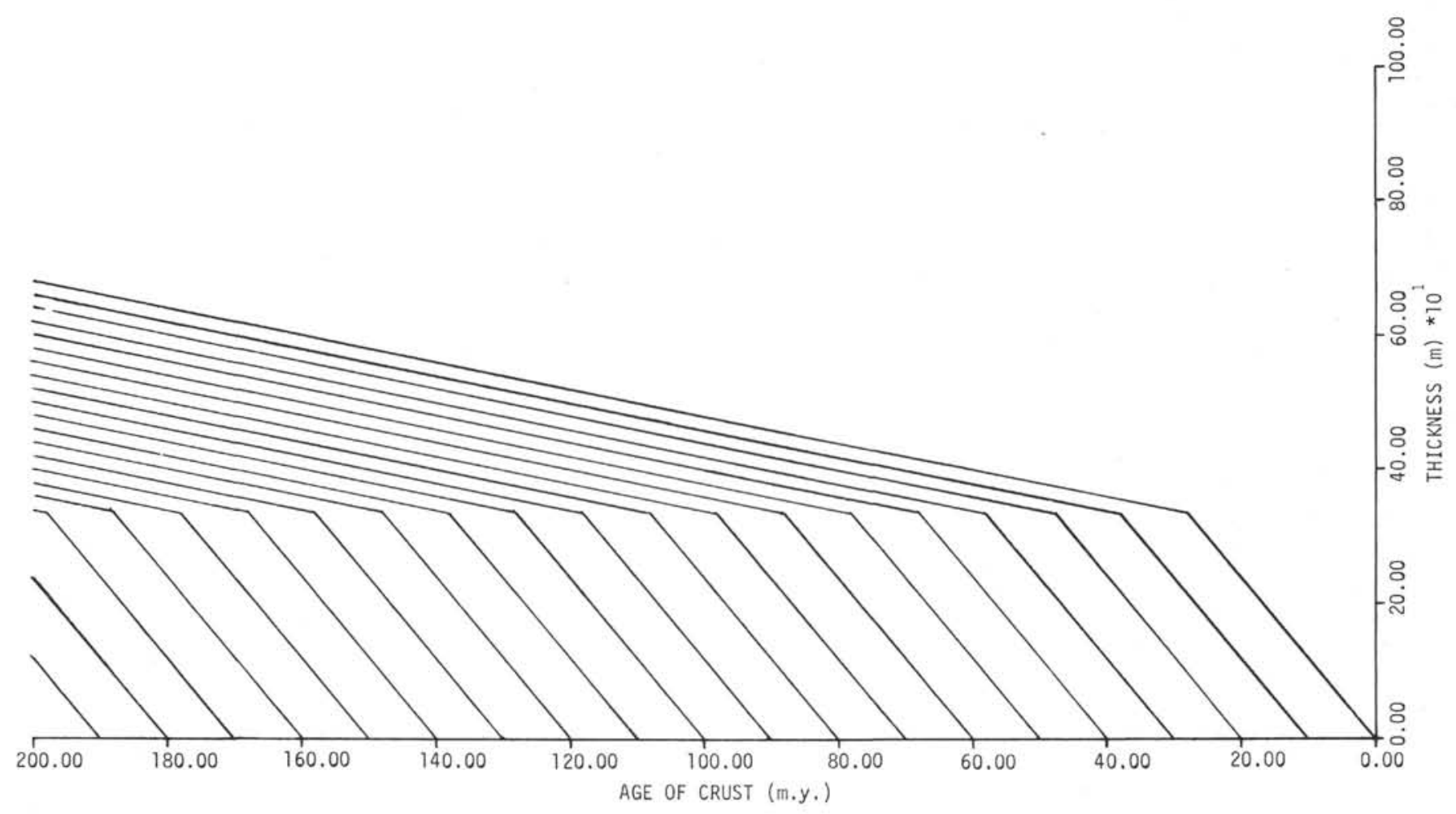

Figure 1. Example with no equatorial passage.

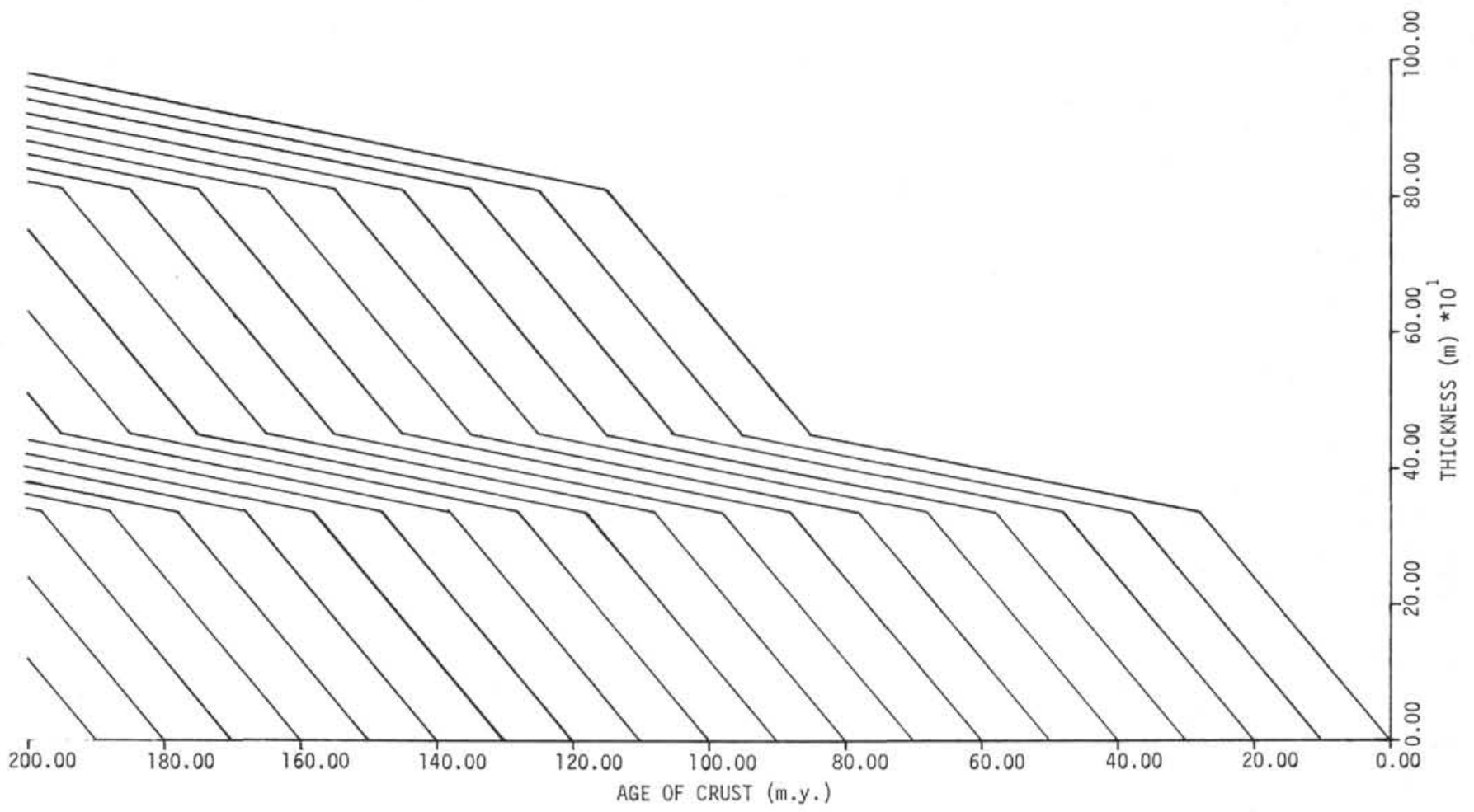

Figure 2. Example with wide equatorial zone. 


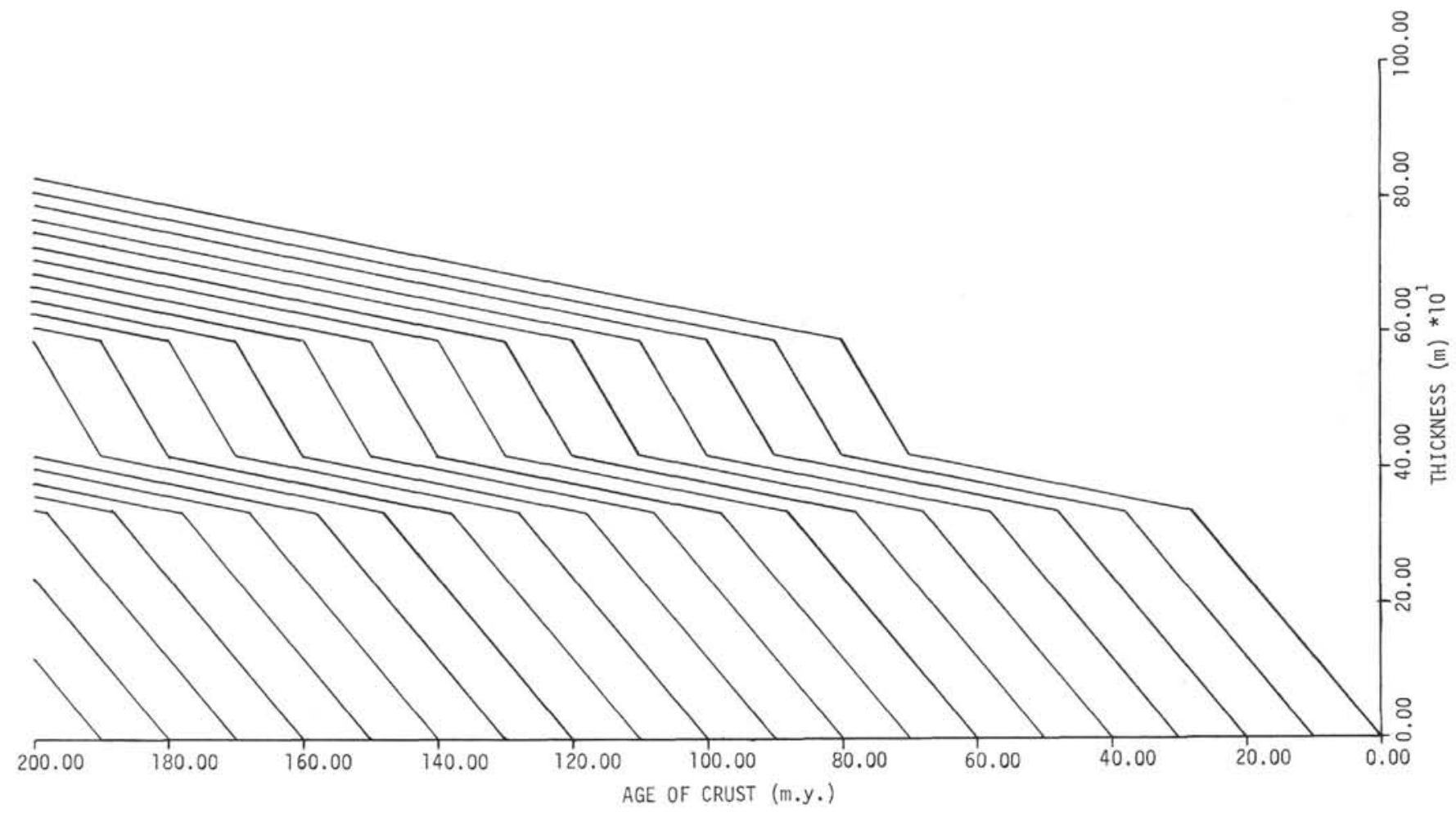

Figure 3. Example with narrow equatorial zone.

reach it after 100 m.y. of motion. The additional carbonate sedimentation rate under the equator is taken as $10 \mathrm{~m} / \mathrm{m}$.y. These parameters result in all crust older than about 90 m.y. being covered with two separate carbonate layers separated by a relatively thin layer of abyssal clay. Thus a borehole through the crust $140 \mathrm{~m}$.y. old would show low sedimentation rate until the sediment recovered was 20 m.y. old, rapid sedimentation down to $60 \mathrm{~m} . \mathrm{y}$. old material, another slow rate down to 120 m.y., and finally another high rate down to basement.

In Figure 3 the equatorial zone is only 10 m.y. wide centered 75 m.y. from the ridge crest, the the equatorial sedimentation rate is $15 \mathrm{~m} / \mathrm{m} . \mathrm{y}$. The narrow equatorial zone could be due to rapid plate movement or the section drawn crossing the equator nearly perpendicularly. The result is that the upper zone of rapid sedimentation associated with the equator is much thinner.

\section{PRELIMINARY MODELS FOR THE NORTH PACIFIC}

The cruises of the Deep Sea Drilling Project have produced much useful information for the construction of a model of the north Pacific. Figure 4 summarizes the data available in the Initial Reports including this volume. The sections are drawn at an angle matching the fracture zones which are taken to be perpendicular to the spreading axis. We will seek to model those sections which cross the $160^{\circ} \mathrm{E}$ meridian at $0^{\circ}, 15^{\circ}$, and $30^{\circ} \mathrm{N}$ latitude, and which will be denoted by the labels $0^{\circ}, 15^{\circ}$, and $30^{\circ}$.

Consideration of the crustal ages determined at various locations leads to a half-spreading rate

$$
S_{p}=6.1 \mathrm{~cm} / \mathrm{yr}=0.55^{\circ} / \mathrm{m} . \mathrm{y} .
$$

Thus the crust at $160^{\circ} \mathrm{E}$ is interpreted as being about 165 m.y. old. The width of the equatorial zone of increased productivity is taken to be $5^{\circ}$, but since the ridge and equator make an angle $\theta$ such that $1 / \cos \theta=5$, the effective width of the equatorial zone projected on the plate is

$$
W=5^{\circ}\left(\frac{1}{0.55} \cdot \frac{\mathrm{m} \cdot \mathrm{y} .}{\circ}\right) \frac{1}{\cos \theta}=45 \text { m.y. }
$$

Since the spreading direction has a component southward from the ridge, the plate moves southward with respect to the ridge at a speed

$$
S_{s}=0.55 \cos \theta=0.11^{\circ} / \mathrm{m} . \mathrm{y} .=1.22 \mathrm{~cm} / \mathrm{yr}
$$

However, plate motions are relative, and from the sedimentary record it is apparent that the whole north Pacific plate-ridge system has been moving northward under the geographical equator. If the plate actually moves northward with respect to the equator with a speed $S_{e}$, then the speed of the equator along the section with respect to the ridge axis is

$$
S=\frac{S_{s}+S_{e}}{6.1 \cos \theta}
$$

expressed as a multiple of the spreading speed.

To complete the specification of the model, we also need to know the location of the equator 200 m.y. ago, when the model begins. Since on the $0^{\circ}$ section the equator 


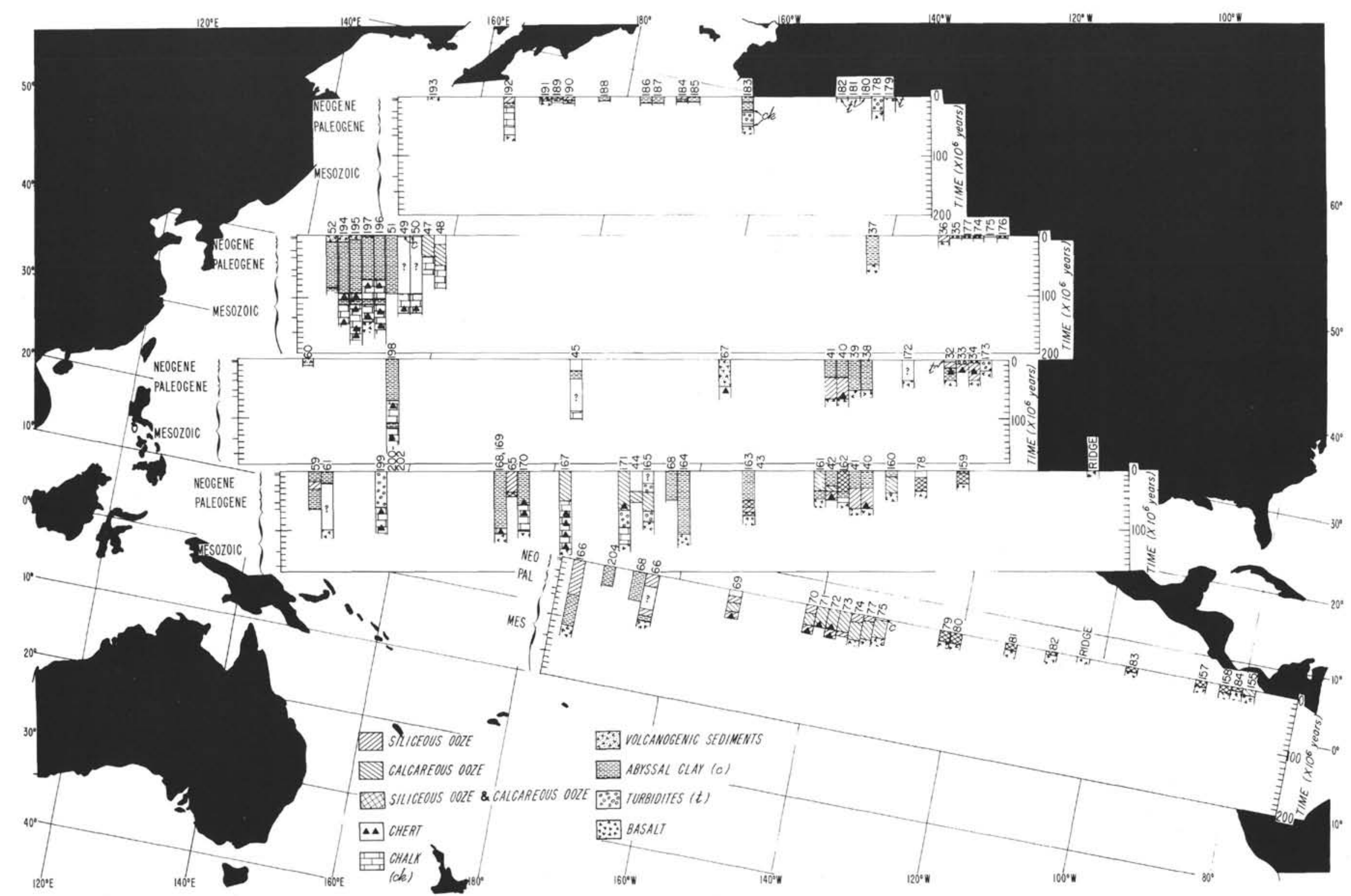

Figure 4. DSDP Pacific sites. 
is at 165 at present, its starting point must be determined by

$$
T_{e}^{0}+200 S=165
$$

Each of the sections will have the same parameters except that the more northern sections must have an adjusted zero point for the equator since they cross it at an earlier time. Thus,

$$
T_{e}^{15}=T_{e}^{0}+\frac{15^{\circ}}{0.55 \cos \theta}
$$

and

$$
T_{e}^{30}=T_{e}^{0}+\frac{30^{\circ}}{0.55 \cos \theta}
$$

Experimentation showed that a reasonably good fit with the data could be made with a northward component of plate motion $S_{e}=3 \mathrm{~cm} / \mathrm{yr}$, corresponding to $S=3.46$ and $T_{e}^{0}=-527$. The negative sign means that 200 m.y. ago the equator crossed the continuation of our section on the other side of the ridge axis. For the other parameters, we took

$$
\begin{array}{ll}
\text { Depth of crustal formation } & =3000 \mathrm{~m} \\
\text { Compensation depth } & =3700 \mathrm{~m} \\
\text { Subsidence rate } & =35 \mathrm{~m} / \mathrm{m} . \mathrm{y} . \\
\text { Abyssal chay sedimentation rate } & =1 \mathrm{~m} / \mathrm{m} . \mathrm{y} . \\
\text { Ridge crest sedimentation rate } & =10 \mathrm{~m} / \mathrm{m} . \mathrm{y} . \\
\text { Equatorial sedimentation rate } & =10 \mathrm{~m} / \mathrm{m} . \mathrm{y} .
\end{array}
$$

to produce the sections shown in Figure 5.

The data available are sufficiently scattered so that only qualitative comparisons are productive. However, it is evident that the equator in the model was near our holes in the northwest Pacific too long ago, but moved too rapidly in the last several million years to accurately match the observations in the eastern equatorial Pacific. To remedy this condition, it is necessary for the northward speed of the plate to change at some time, likely 30 m.y. as marked by the change in direction of seamount chains (Jackson, 1972). Experimentation produced a good fit for a northward component. of plate motion of $2 \mathrm{~cm} / \mathrm{yr}$ between the present and $30 \mathrm{~m} . \mathrm{y}$. ago and $4 \mathrm{~cm} / \mathrm{yr}$ prior to $30 \mathrm{~m} . \mathrm{y}$. ago. This corresponds to speeds $S$ of 2.63 and 4.27 , respectively. Using the other parameters as above, the graphs of Figure 6 are produced. This model matches the general features discovered by drilling rather well.

There is evidence that the basal carbonate layer in the central Pacific is very thin or altogether absent. The likeliest explanation for this phenomena is that the compensation depth rose near or above the ridge crest for a period of time, perhaps as a result of climatic changes. The program was modified to include this feature between 60 and 100 m.y. ago, and the predictable results are shown in Figure 7.

As an example of the sort of detail that might be incorporated into the model as more data become available, let us consider the apparent unconformities $60 \mathrm{~m} . \mathrm{y}$. ago at Site 171 and 65 m.y. ago at Site 199. A possible explanation for the unconformities is that the motion of the plate with respect to the equator reversed itself for a short period of time. Let us postulate that between 50 and 60 m.y. ago the plate moved southward with respect to the equator at $5 \mathrm{~cm} / \mathrm{yr}$, or $S=-3.10$. Between now and 30 m.y. ago we still take $S=2.63$, and to compensate for the backward motion, the speed at all other times is $S=5.18$.

The results are shown in Figure 8. Note the slight unconformity between equatorial sequences above the 165 m.y. old crust on the $15^{\circ}$ section. Crust slightly younger has a more pronounced unconformity, matching the scanty data available. We do not have nearly enough information to prove the brief reversal of plate motion, but it is an interesting possibility.

\section{CONCLUSIONS}

A mathematical model of sediment accumulation on a moving plate is an easily used and useful tool for the interpretation of age versus thickness of sediment information gained through deep sea drilling. Using it, we have given a strong case for the northward motion of the Pacific plate for the last 200 m.y. and deduced some general features of that motion. New data can easily be incorporated in the modeling method and will produce more detailed information concerning plate motions.

\section{REFERENCES}

Arrhenius, G., 1952. Sediment cores from the East Pacific: Rept. Swedish Deep-Sea Exped., Goteborg (V. Goteborgs Kungl. Vetenskaps-och Vitterhets-Sanhalle).

Berger, W. H., 1967. Foraminiferal ooze: solution at depth; Science, v. 156 , p. 383-385.

Heezen, B. C., MacGregor, I. D., Forman, H. P., Forristall, G. Z., Hekel, H., Heese, R., Hoskins, R.H., Jones, E. J. W., Kaneps, A., Krasheninnikov, V. A., Okada, H., and Ruef, M.H., 1973. Diachronous deposits: A kinematic interpretation of the post Jurassic sedimentary sequence on the Pacific plate: Nature, v. 241, p. 25.

Jackson, E. D., Silver, E. A., and Dalrymple, B. B., 1972. Hawaiian-Emperor chain and its relation to Cenozoic circum Pacific tectonics: Geol. Soc. Am. Bull., v. 83, p. 601-618.

Peterson, M. N. A., 1966. Calcite: rates of dissolution in a vertical profile in the central Pacific: Science, v. 154, p. 1542-1544.

Winterer, E. L., 1972. Geologic History of the Pacific Ocean: Am. Assoc. Petrol. Geol. Bull., v. 56, p. 63. 


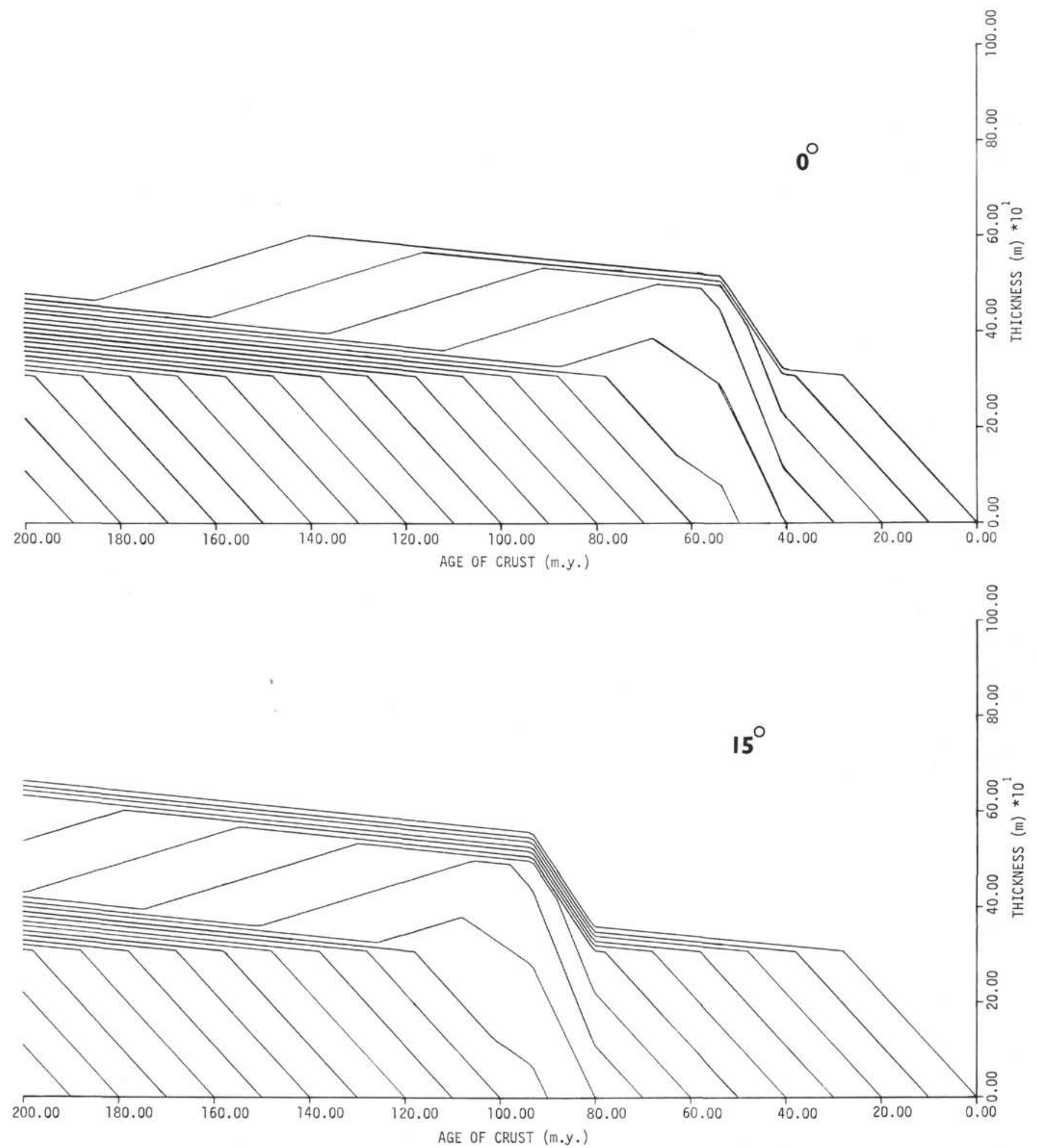

Figure 5. Model with constant northward plate motion. 


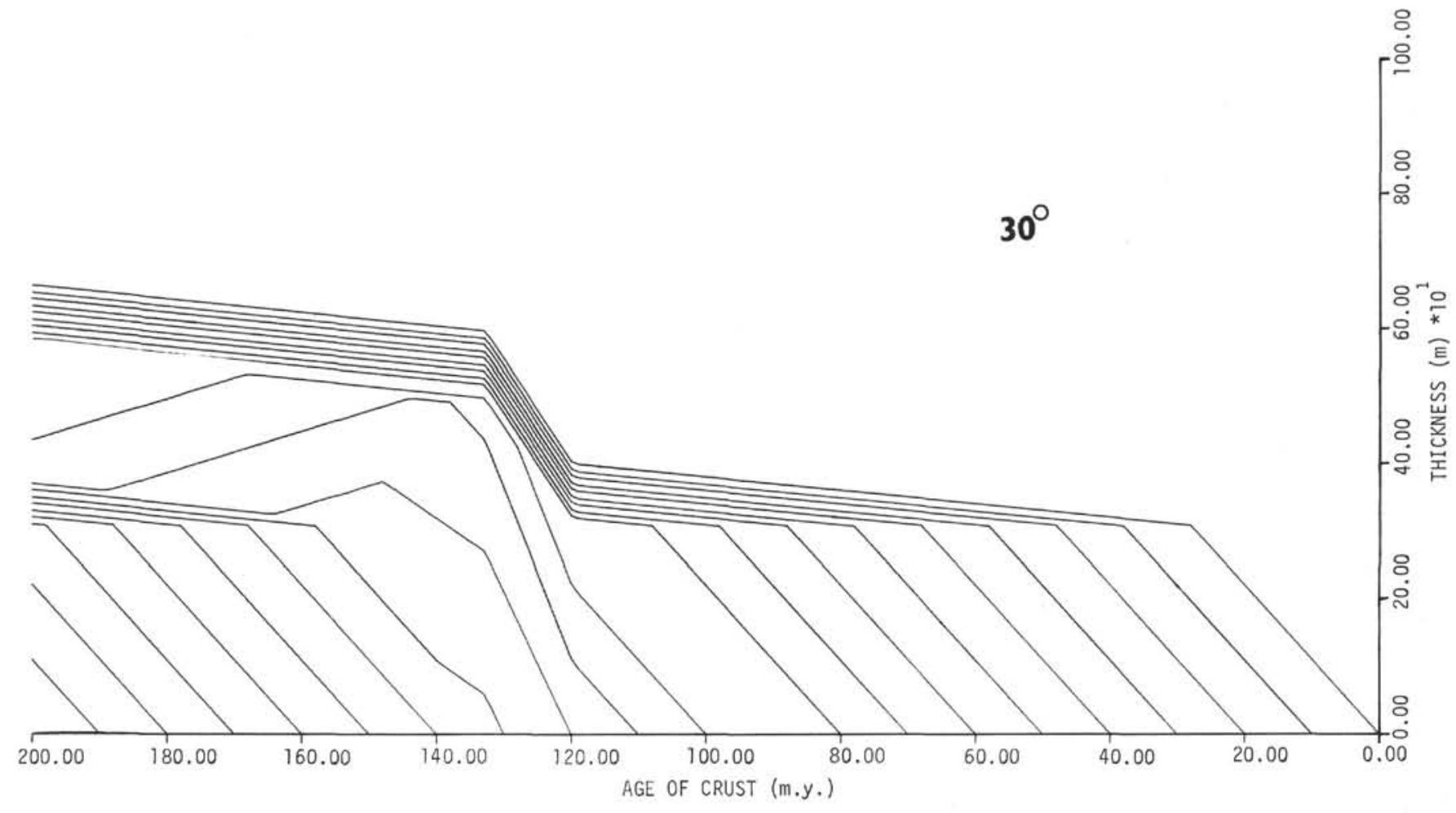

Figure 5. (Continued).

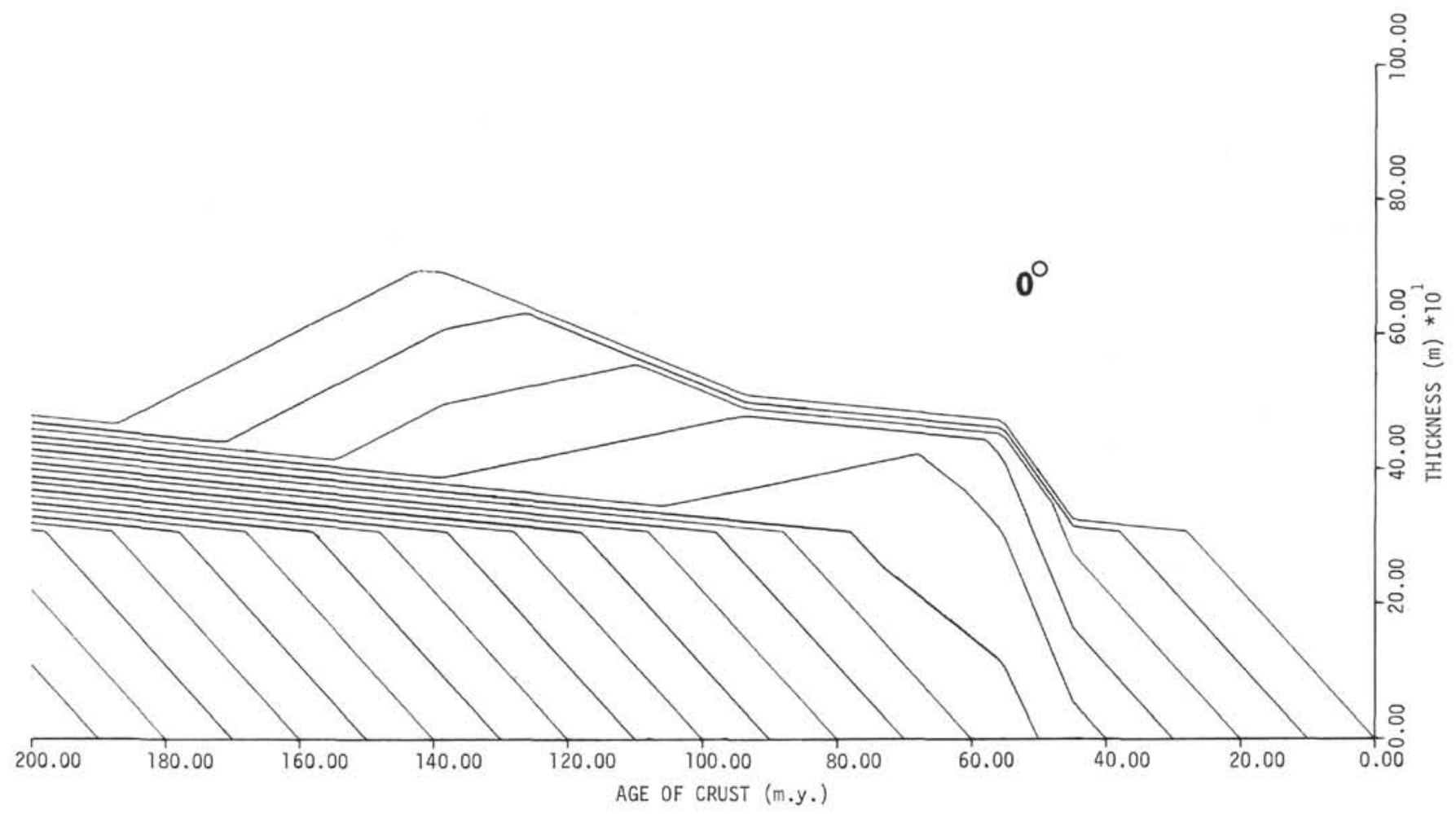

Figure 6. Model with increased northward plate motion. 


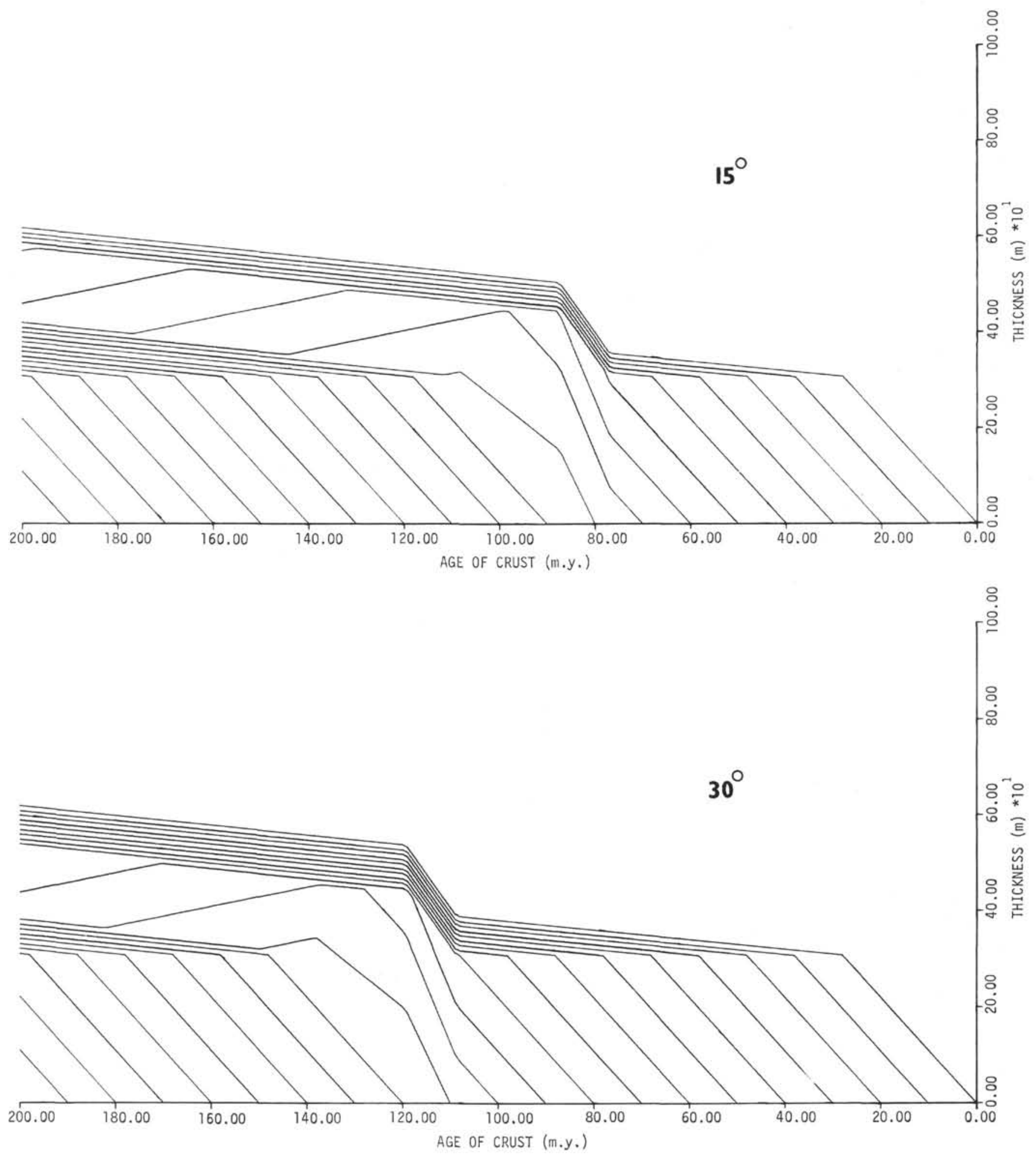

Figure 6. (Continued). 

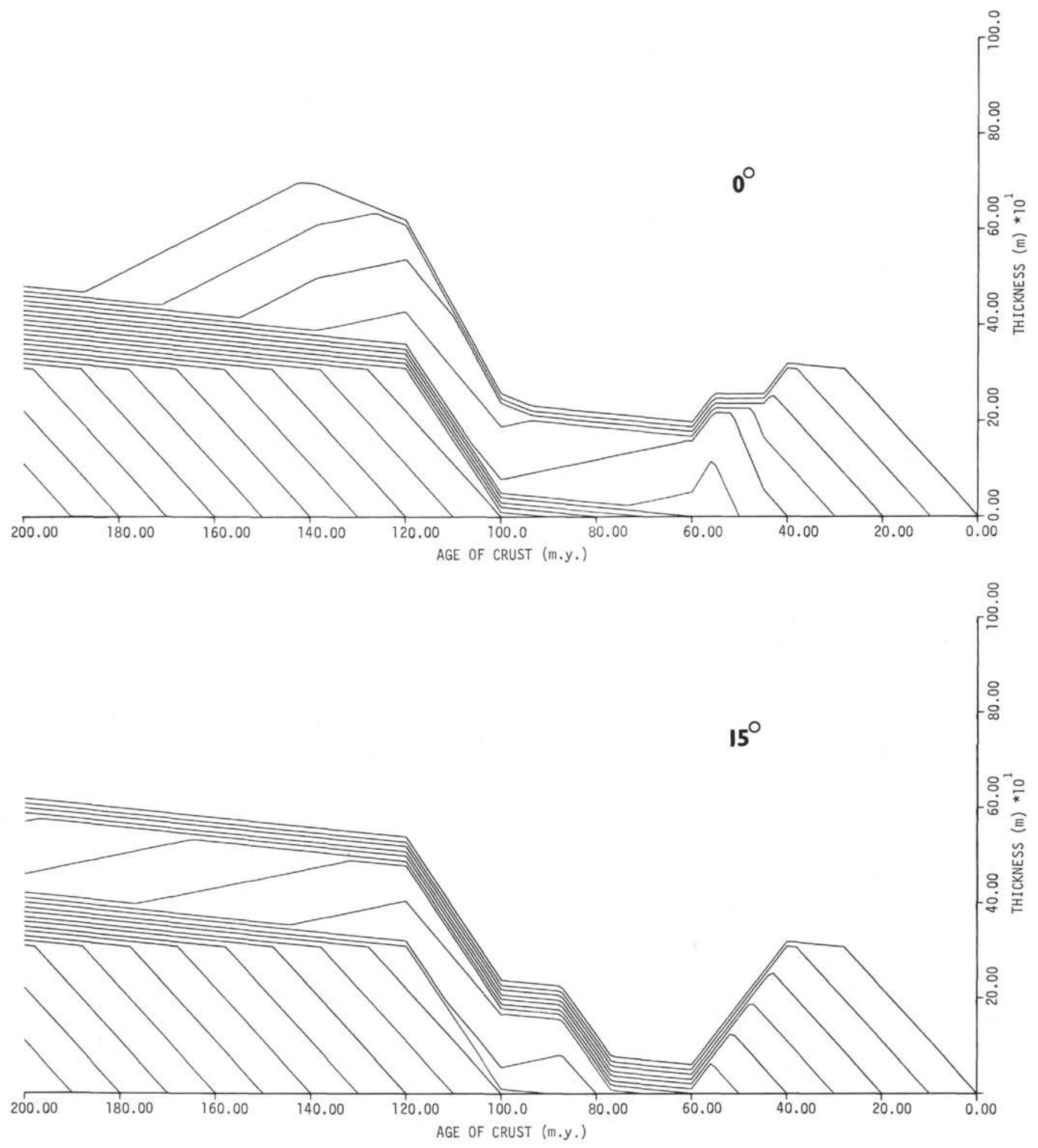

Figure 7. Model with raised compensation depth. 


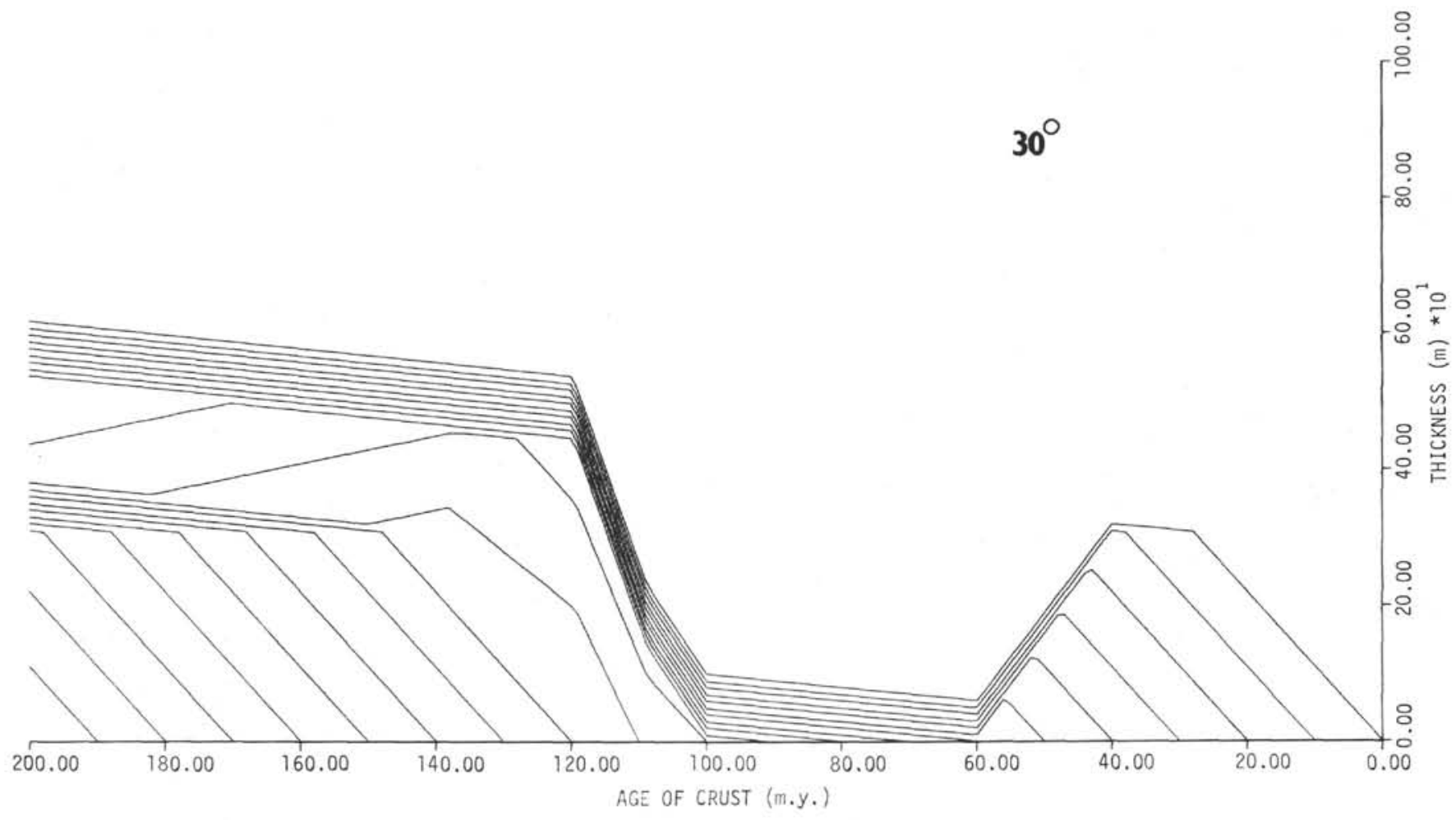

Figure 7. (Continued).

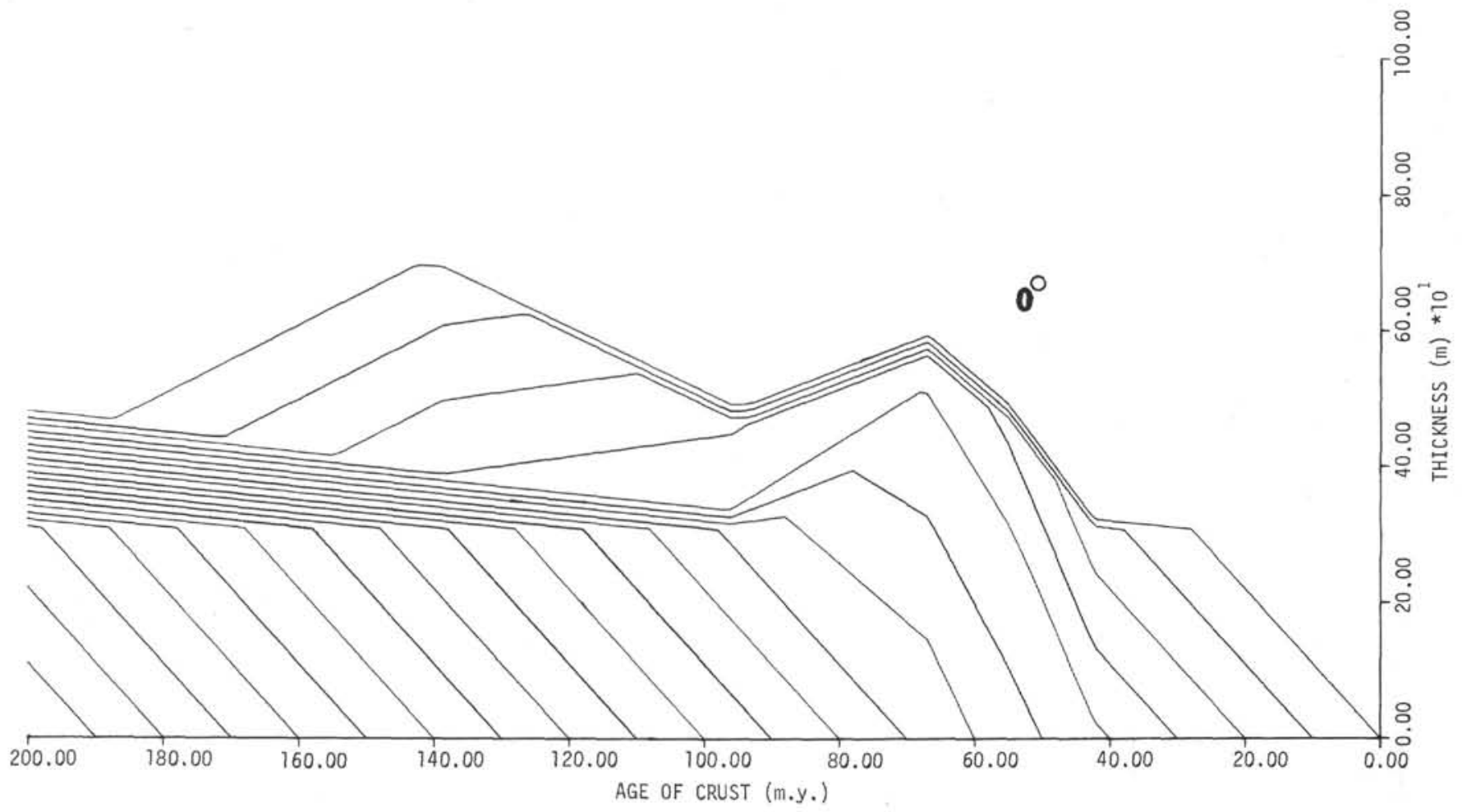

Figure 8. Model with southward plate motion 50 to 60 m.y. ago. 


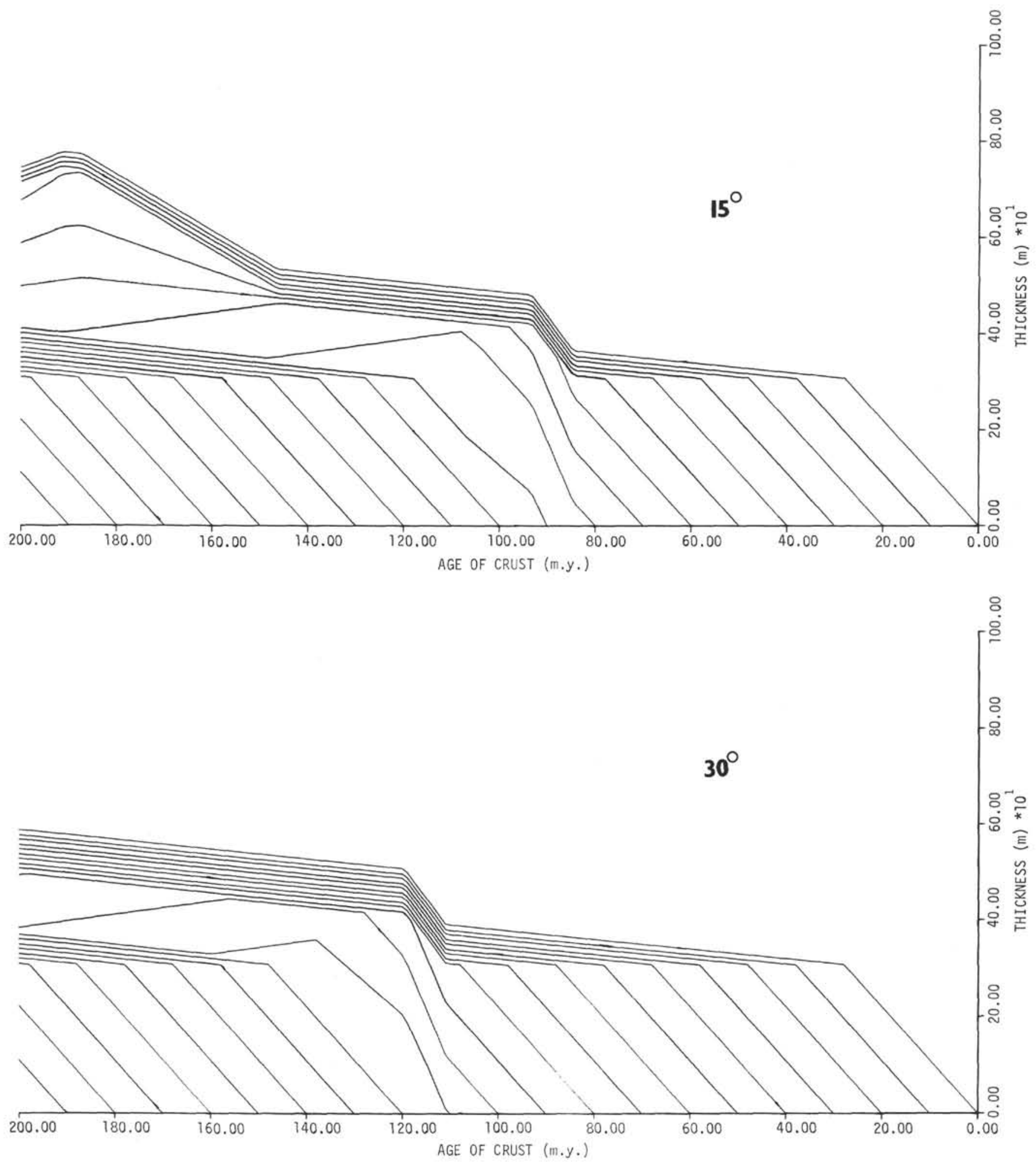

Figure 8. (Continued). 


\section{APPENDIX: COMPUTER PROGRAM}

A FORTRAN IV computer program is presented here which performs the calculations discussed in the main body of the text and automatically plots the output. The plotting subroutines are those supplied in the standard CALCOMP package. Following the listing of the program is a sample of input data which produced Figure 6 and an explanation of the use of the program. It requires only a few seconds running time on a UNIVAC 1108 system.

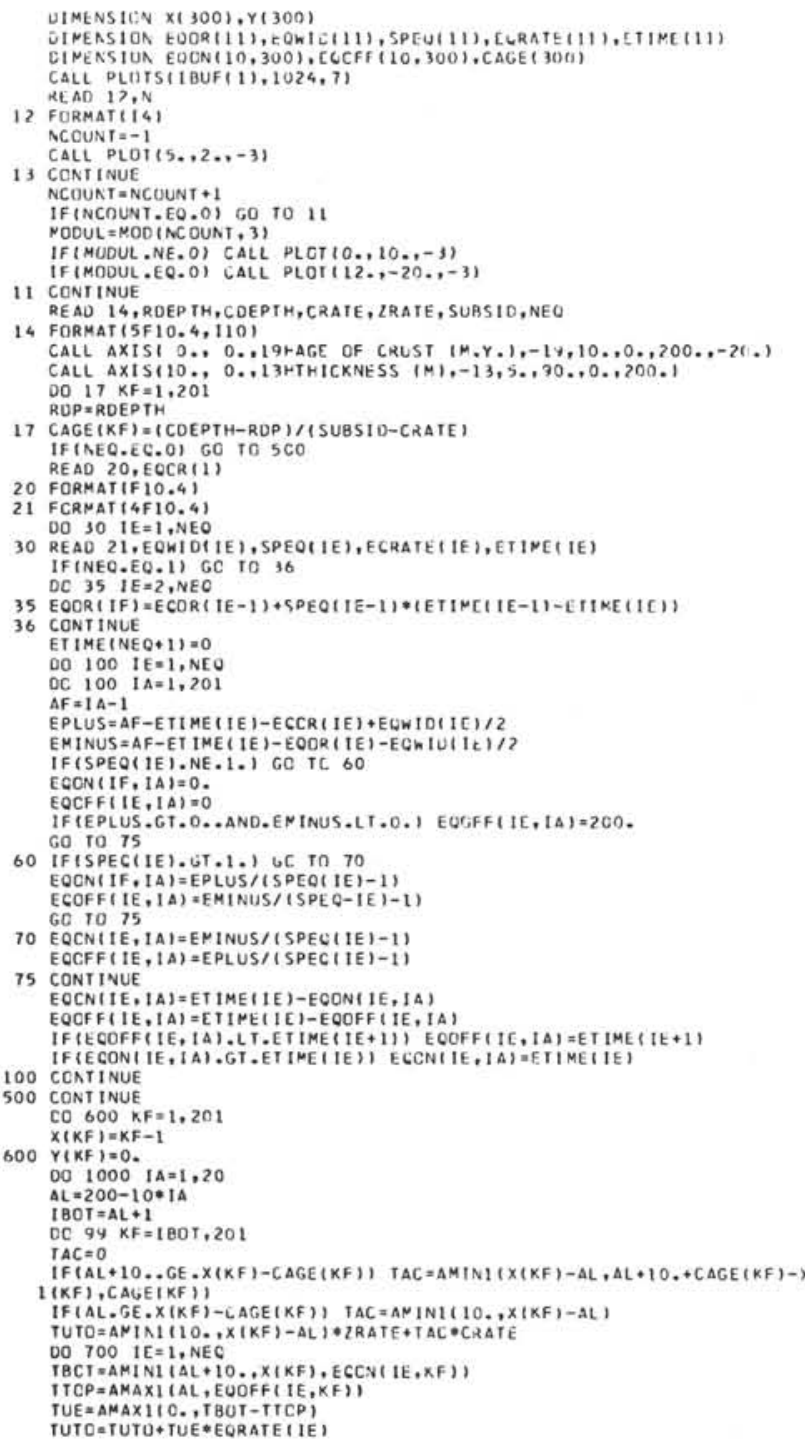

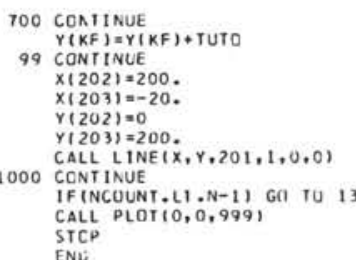

\begin{tabular}{|c|c|c|c|c|}
\hline 3000. & 3700 . & 10. & 1. & 35. \\
\hline & $\begin{array}{l}4.27 \\
2.63\end{array}$ & $10:$ & $\begin{array}{l}200 . \\
330 .\end{array}$ & \\
\hline $\begin{array}{c}3000 . \\
-503.4\end{array}$ & 3700. & in: & i. & 35. \\
\hline $\begin{array}{l}45 . \\
450\end{array}$ & $\begin{array}{l}4.27 \\
2.63 \\
1700 .\end{array}$ & $\begin{array}{l}10: \\
10:\end{array}$ & $\begin{array}{l}200 . \\
\text { ce. } \\
\text { t. }\end{array}$ & \\
\hline $\begin{array}{l}3000 . \\
-653.9 \\
45 .\end{array}$ & & 10. & 200. & 35. \\
\hline
\end{tabular}

The first data card simply lists the number of problems to be worked in the run, where each section is considered a separate problem. There follows a set of data cards for each problem, in this case three sets. The first card of each set contains the following general information in FORMAT $(5 \mathrm{~F} 10.4, \mathrm{I10})$ :

RDEPTH - the depth of crustal formation, $F$

CDEPTH - the carbonate compensation depth, $C$.

CRATE - the rate of organic deposition above the compensation depth, $R_{C}$

ZRATE - the rate of abyssal clay deposition, $R_{a}$

SUBSID - the crustal subsidence rate, $R_{S}$

$\mathrm{NEQ}$ - number of changes in equator parameters

If $\mathrm{NEQ}=0$, the equator does not enter into the problem and no equator cards need be included. Otherwise, the program requires one card giving

EQOR - location of equator 200 m.y. ago, $T_{e}$

in FORMAT (F10.4) followed by NEQ cards giving the following equatorial parameters in FORMAT (4F10.4):

EQWID - width of equatorial zone, $W$

SPEQ - speed of equator relative to ridge crest, $S$

EQRATE - extra rate of organic sedimentation under equator ETIME - time before present at which the parameters of this card become applicable.

The program is written so that the starting time for the model, $T_{o}$, is $200 \mathrm{~m} . y$. before present, but it may be modified in an obvious way for other starting times. Special features can be easily incorporated in the relatively simple coding of the program. 